\title{
Contamination of Malting Barley by Toxigenic Fungi of Genera Fusarium and Cochliobolus
}

\author{
Olga Ivanchenko \\ Higher School of Biotechnology and Food Technology \\ Peter the Great St. Petersburg Polytechnic University, \\ 194021, Russia, St.Petersburg, Novorossiyskaya, 48-50
}

\author{
Olga Baranova \\ Federal State Budget Scientific Institution \\ “All-Russian Institute of Plant Protection", (FSBSI VIZR), \\ 196608, Russia, St.Petersburg, Pushkin, Podbelskogo, 3
}

\author{
Marina Danina \\ Saint Petersburg National Research University \\ of Information Technologies, Mechanics and Optics \\ University (ITMO) \\ Russia, Saint Petersburg, Kronverksky Pr. 49
}

\begin{abstract}
Nowadays investigations of safety assessment of foods might be carried out using nanotechnologies. Apart from medical diagnostics, PCR is now used in investigations of genetics analysis, discovering of genetically modified products and identification of microbial contaminants of food material. Contamination of malting barley by toxigenic microorganisms is of immediate interest for brewing industry. In this work we investigated grains of Russia-specific malting barley Benthe and Cherio of 2015 and 2016 harvesting years. "Germination abilities" of Benthe and Cherio seeds of the crop of 2015 and 2016 were low: $65.8 \%$ and $76 \% ; 62.8 \%$ and $78 \%$, respectively. Starch content in grains conforms to standards regardless the harvesting year and protein content of Bente of 2016 exceeds the regulated characteristics. Phytopathogenic microbial contamination of grain is mainly presented by fungi of Fusarium genus and Cochliobolus sativus species, but correlation between these phytopathogenic fungi varies depending on the harvesting year. Using species-specific primers in PCR we defined belonging of fungi of Fusarium genus to toxigenic Fusarium graminearum species for three Benthe samples of the $\mathbf{2 0 1 6}$ harvesting year and for nine Cherio samples of the $\mathbf{2 0 1 6}$ harvesting year.
\end{abstract}

Keywords-malting barley; Fusarium fungi; food quality; germination energy; toxigenic microorganisms

\section{INTRODUCTION}

Modern investigations on food quality and safety assessments might be performed using nanotechnologies. In nanobiotechnologies PCR is widely used for obtaining large amounts of specific DNA sequences for various applications. Nowadays apart from medical diagnostics, PCR is used in research studies for gene cloning; DNA sequencing; for genetics analysis; discovering of genetically modified products and identification of toxigenic contaminants of food material, etc. [1-8].
Nowadays brewing industry of Russia is rapidly developing, and provision of raw material of appropriate quality is of immediate interest. Barley remains traditional grain crops used for production of malt and beer and now it is widely investigated [9].

High sensibility of grains to a complex of pathogenic and saprophite microorganisms is one of the reasons for low quality of malting barley. This sensibility results in a change of chemical composition of grain, significant reduction of its vital ability and quality degeneration of both raw material and the end beverage. There are a lot of of microorganisms, which contaminate the grains: yeast, actinomycetes, filamentous fungi, protozoans, algae. But these are fungi which play a crucial role in grain damage, though its content is less than $1 \%$ of the total grain microflora [10-12]. They intensively cultivate on the surface and under the grain coating, thus damaging the covering tissues and reserved barley substances and changing its quality. At this, the grain temperature raises up to auto-ignition, active loss of dry substances takes place. As far as the damage is enhanced and typical odor appears, acidity of grain increases, its fermentation ability reduces and starch content reduces, protein substances decompose $[13,14]$. Such barley cannot be used for malt production.

The fungi of the genera Alternaria, Bipolaris, and Fusarium are dominated among the field fungi on the grains of malting barley.

The fungi Cochliobolus sativus is a teleomorph (the sexual reproductive stage) of Bipolaris sorokiniana (anamorph) and causes a vast variety of diseases of grains. The fungi may infect and cause diseases of roots (where it is known as common root rot), leaves (dark brown spot), as well as the head and grains. 
While assessing the malting barley infection rate by Fusarium, we distinguish infected grain and the damaged one [15]. In the first case we mean grains which contain Fusarium in external or internal microflora (conidium or mycelium) but have all outward attributes of healthy grains and high germination ability. In the second case under the term "damaged grain" we mean fusarial grain. Malting barley must not contain any fusarial grain.

In central, west, north-west areas of Russia, as well as in Belorussia, the fungi of the Fusarium spp. genus are presented on almost all grains and in a rather large amount. Among the population of fungi of Fusarium genus, the Fusarium sporotrichiella var. Poae, F. sporotrichiella var. Tricinctrum are prevalent in the Central Russia. Along with them but in smaller amounts F.sambucinum var. Minus and Flateritium were derived [16].

Toxical substances (mycotoxines) are often discovered during molding in grains. They are secondary metabolites of microscopic fungi considered among the most harmful for human health. Its potential danger significantly increases due to its high stability to boiling, and treatment by mineral acids, alkali and other reagents.

Infection of grains might affect the technological process, and cause beer gushing, and mycotoxines may affect yeast properties [17].

The highest toxical impact of mycotoxins is seen in newlythreshed grain. At its storage in dry condition its toxical action becomes weaker, but toxins remain its activity in barley for some years and thermal treatment often does not result in its total decomposition $[18,19]$.

Mycotoxins possess mutagenic, cancerogenic and often teratogenic properties $[15,20]$. Not coincidentally mycotoxins have been included in the regulated list of food products, feed and raw materials [21]. Grain and its products can be polluted by some mycotoxins simultaneously. And if one substance in such a low concentration may not have a negative impact, but cumulatively these "harmless" doses of substances may possess a rather harmless impact [22].

From March 1998 to March 2002, the researchers from Canada analyzed by the content of aflatoxins B1, B2, G1, G2 304 the beer samples both coming onto Canada market and produced there. The aflatoxin content was increased in 12 samples: 4 beer samples from Mexico, 2 - from Spain and 1 from Portugal contained aflatoxin B1. 4 beer samples from India contained aflotoxins B1 and B2 [23]. High level of zearalenone - $0.92 \mathrm{mg} / \mathrm{l}$ - was discovered in Zambia in corn beer [10].

Thus, one of the main tasks in production of malting barley is not to admit evolution of microorganisms in it or to slow down its vital biochemical processes, but to the fullest extent possible preserve malting properties of grains.

\section{MATERIALS AND METHODS}

In this work we studied grains of malting barley: Cherio, which is area-specific for Central and North-West regions of Russia and Benthe of the 2015 and 2016 harvesting years.
These years were very different in weather conditions (2016 was rainy and very favorable for growth of pathogenic organisms, especially fusarial fungi). Sampling was performed according to the Russian State Standard GOST 12036-85 [24].

Estimation of the sprouting energy (germination ability) was performed according to the Russian State Standard GOST 12038-84 [25]. The seeds of basic culture were separated from batch weight while determining its purity degree. From these seeds of basic culture we selected 4 samplings, which comprised 100 seeds in each one [26]. Seeds germination was carried out according to the MB technique (between paper sheets). The seeds were placed in the growth chambers between the sheets of damped filtering paper: two-three layers were put on the bottom of the growth chamber, one layer was used to cover the seeds. Seeds germination was carried out at temperature $22 \pm 2{ }^{\circ} \mathrm{C}$ for $7-10$ days in thermostats with forced ventilation. Further we carried out estimation and accounting of the sprouted seeds, as well as determined the germination energy and ability. Germinated seeds of healthy view and well-developed roots (or the main embryo root) were attributed to viable seeds.

Biochemical estimation of malting barley grains. Protein and starch contents were determined by infrared microscopy using Infratec 1241 (Sweden). The results are provided by the department of biochemistry and molecular biology of AllRussian Research Institute of Plant Industry (Saint-Petersburg, Russia).

\section{MATHEMATICAL PROCESSING OF RESULTS}

Determination of reliability of differences between two independent results was carried out using t-criterion of Student.

\section{A. Obtaining of pure fungi cultures and extraction of pathogene}

In this work we used potato-glucose agar (PGA), which had the following content: potato - $400 \mathrm{~g}$; glucose - $20 \mathrm{~g}$; bacteriological agar - $20 \mathrm{~g}$, distilled water - up to 11 . Medium preparation was as follows: peeled potato was boiled in distilled water. Then the obtained decoction was filtered and after $20 \mathrm{~g}$ of glucose and agar were added. The medium was autoclaved at $1.0 \mathrm{~atm}$ pressure for 30 minutes. Nutrient sterile broth was poured out to petrie dishes.

For removal of surface microflora and spores we carried out sterilization of grain surface. Grains were washed out under running water with surface active agent and then without it. After this the grain was sterilized by $5 \%$ hypochlorite of sodium $(\mathrm{NaOCl})$ for 5 minutes. After this treatment the grains were washed in sterile water. Then they were dried using the sterile filtering paper and rapidly moved above the flame [27]. 10 grains were put on the stabilized medium using a sterile pincer. This work was carried out in a laminar box (NuAire, USA). Petrie dishes were incubated at temperature $22 \pm 2{ }^{\circ} \mathrm{C}$ for $7-10$ days for formation of conidia. 


\section{B. DNA isolation and pathogene identification by PCR technique}

DNA for molecular investigations were extracted from myceliar mass of fungi. For DNA extraction we used CTAB method [27]. This method is based on ability of nucleic acid to form solvable complexes with CTAB detergent (Cetrimonium bromide) in conditions of high salt concentration. Reduction of salt concentration causes precipitation of these complexes. At this, DNA is purified from pigments and polysaccharides, which remain in the solution. RNA elimination is carried out by RNAases' treatment [28].

\section{Extraction protocol was as follows:}

1. Fungi micellium was grinded in the eppendorf test tube with 2 CTAB buffer $(700 \mu l)$ and was well-mixed. Quantitative composition of the buffer is presented in Table 1.

2. The test tubes were incubated at $65.5^{\circ} \mathrm{C}$ for $1 \mathrm{~h}$.

3. Equal volume of chloroform:octanol (24:1) was added and then mixed for $1 \mathrm{~min}$.

4. The test tubes were centrifuged for 2 minutes at $14000 \mathrm{rpm}$.

5. $90 \%$ of the upper phase of the solution was moved to clean test tubes and equal volume of chloroform:octanol was added, then mixed for 1 minute.

6. The test tubes were centrifuged for $2 \mathrm{~min}$ at 14000 rpm. $90 \%$ of the upper phase of the solution was moved to clean test tubes.

7. $600 \mu \mathrm{l}$ of icy isopropanol was added and the mixture was shaken in hands. DNA strands appearance in the solution was observed.

8. The tubes were centrifuged for 1 minute at 14000 rpm. The obtained solution was poured away with monitoring the precipitate. $\mu 1)$.

9. The precipitate was purged with $70 \%$ alcohol (1000

10. The tubes were centrifuged for 1 minute at 12000 $\mathrm{rpm}$. The obtained solution was poured away. The precipitate DNA was dried out and then dissolved in $100 \mu \mathrm{l}$ of $\mathrm{H}_{2} \mathrm{O}$.

TABLE I. COMPOSITION OF 2 XCTAB

\begin{tabular}{|l|l|l|}
\hline Reactive & Concentration & $\mathbf{1 0 0} \mathbf{~ m l}$ \\
\hline CTAB & $2 \%(w / v)$ & $2.0 \mathrm{~g}$ \\
\hline $\mathrm{NaCl}$ & $1.4 \mathrm{M}$ & $8.18 \mathrm{~g}$ \\
\hline Tris $\mathrm{Cl}, p \mathrm{H} 8.0$ & $0.1 \mathrm{M}$ & $10 \mathrm{ml}$ \\
\hline EDTA & $20 \mathrm{mM}$ & $4 \mathrm{ml}$ \\
\hline $\mathrm{H}_{2} \mathrm{O}$ & & up to $100 \mathrm{ml}$ \\
\hline
\end{tabular}

PCR for identification of the Fusarium graminearum fungi in the samples was carried out with genus-specified primers Fg11f/r [27]. Amplification was carried out in the eppendorf test tubes in $20 \mu \mathrm{l}$ of recreational mixture $(20 \mu \mathrm{l}$ of recreational mixture: bidistilled water $-14.14 \mu \mathrm{l}$ mixtured NTPs $(25 \mathrm{mM})-0.16 \mu \mathrm{l}$ primer $\mathrm{R}(10-15 \mathrm{pmol})-0.5 \mu \mathrm{l}$ primer F (10-15 pmol) - $0.5 \mu \mathrm{l} 10 \mathrm{x}$ PCR bufer - $2 \mu \mathrm{MgCl} 2$
(50 mM) - $1.2 \mu \mathrm{l}$; Taq-polymerasa (5 U) - $0.5 \mu \mathrm{l}$; genome DNA $-1 \mu \mathrm{l})$.

For amplification we used thermocycler MyCycler TM (BIO-RAD). Separation of amplification products was carried out using electrophoresis technique in $1.7 \%$ agarose gel, colored by ethidium bromide at $100 \mathrm{~V}$ for 3 hours in a $0.5 \times T B E$ buffer. As markers of molecular weight we used GeneRulerTM 50kb DNA Ladder (Fermentas, Germany).

\section{RESULTS AND DISCUSSION}

At the first stage of our work we analyzed the following characteristics of the malting barley: germination energy and ability. During the grain germination the ferments are formed, which cause main processes in grains: hydrolysis of proteins and starch. One of the reasons for low germination ability might be its contamination by mycelial fungi.

Germination energy factor is often used in brewery as an indicator of physiological mature of grain and its readiness to malting. The amount of malt is directly proportional to intensity and uniformity of grain sprouting. For barley with completed processes of post-harvest maturation the germination energy factor is $95-97 \%$ of the sprouted grains, which have roots not shorter than the grain length. In such grains we see high activity of ferments, which are in charge of starch saccharification, and endosperm dissolving takes place. The results are presented in Table 2 .

TABLE II. GERMINATION ENERGY AND ABILITY OF BARLEY GRAINS

\begin{tabular}{|l|l|l|}
\hline Grade, year & Germination energy, \% & Germination ability, \% \\
\hline Benthe, 2015 & 90.8 & 65.8 \\
\hline Benthe, 2016 & 97.0 & 76.0 \\
\hline Cherio, 2015 & 91.0 & 78.0 \\
\hline Cherio, 2016 & 88.0 & 62.8 \\
\hline
\end{tabular}

While estimating the germination energy factor, we took into account only sprouted grains, while germination ability is characterized by the amount of grains with healthy sprouts.

As it is seen from table 3 , the average values of germination ability both for the 2015 and 2016 harvesting years were low -65.8 and $76.0 \%$ for Benthe, and 78.0 and $62.8 \%$ for Cherio, respectively. At this, the standard germination ability for barley according to the Russian State Standard GOST R 52325 - 2005 should be not less than $92 \%$.

It was shown that there were no reliable differences for germination parameters and sprouting energy of Benthe and Cherio of the 2015 and 2016 harvesting years while comparing the samplings of various years of each grade. So, tcriterion of Student for germination energy of Benthe of the 2015 and 2016 harvesting years is $\mathrm{t}=2.1$, and for Cherio $\mathrm{t}=0.5 \quad(\mathrm{P}>0.05)$. For germination ability we also showed absence of reliable differences between samplings of the years 2015 and 2016. For Benthe $t=0.7(\mathrm{P}>0.05)$, and for Cherio $\mathrm{t}=0.9(\mathrm{P}>0.05)$.

We carried out analysis of biochemical characteristics of the grain quality: starch and protein contents. The results for biochemical grain assessment are presented in Table 3. 
One of the major economical and chemical factors during malt quality assessment is extract output, which is directly proportional to protein and starch contents in it. Usage of barley with high content of extraction substances allows one to obtain higher beer output from the same material amount. Quantative contents of starch and protein are of high technological importance. Barley with $9-12 \%$ protein content is used for brewing [29]. Oscillations in protein content in grains result in difficulties in its processing during malting.

Starch content is $50-65 \%$ of the dry substance and determines its production and economical importance. Russian malting barleys usually contain $60-64 \%$ of starch, which corresponds to extraction rate $78-82 \%$.

As it is seen from Table 3 for both analyzed grades, the starch contents in grains conform to standards regardless the harvesting year. And protein content in Benthe of the year 2016 exceeds these standards.

TABLE III. PROTEIN AND STARCH CONTENTS IN BARLEY GRAINS OF BENTHE AND CHERIO GRADES

\begin{tabular}{|c|c|c|c|c|}
\hline \multirow[b]{2}{*}{ No. } & \multirow[b]{2}{*}{ Grade name } & \multirow[b]{2}{*}{ Harvesting year } & \multicolumn{2}{|c|}{ Content, \% } \\
\hline & & & protein & starch \\
\hline 1 & Benthe & 2015 & 10.9 & 65.1 \\
\hline 2 & Benthe & 2016 & 12.4 & 61.3 \\
\hline 3 & Cherio & 2015 & 11.7 & 63.3 \\
\hline 4 & Cherio & 2016 & 12.0 & 64.1 \\
\hline
\end{tabular}

We carried out analysis of internal grain infection by phytopathogenic fungi. The results are presented in Tables 4 and 5.

TABLE IV. INTERNAL CONTAMINATION OF GRAINS BENTHE BY COCHLIOBOLUS SATIVUS AND FUSARIUM SPP

\begin{tabular}{|c|c|c|c|c|c|c|c|}
\hline Year & Dish No. & Sprouting, $\%$ & $\mathrm{X}_{\mathrm{av}}$ & Germination ability, $\%$ & $\mathrm{X}_{\mathrm{av}}$ & Infection, $\%$ & Species composition $(\%)$ \\
\hline \multirow{10}{*}{2016} & 1 & 80 & \multirow{10}{*}{65} & 30 & \multirow{10}{*}{31} & 100 & Cochliobolus sativus 60/ Fusarium spp 40 \\
\hline & 2 & 60 & & 40 & & 100 & Cochliobolus sativus 50/ Fusarium spp 50 \\
\hline & 3 & 70 & & 50 & & 100 & Cochliobolus sativus 30 / Fusarium spp 70 \\
\hline & 4 & 60 & & 20 & & 100 & Cochliobolus sativus 30/ Fusarium spp 70 \\
\hline & 5 & 60 & & 40 & & 100 & Cochliobolus sativus 20/ Fusarium spp 80 \\
\hline & 6 & 60 & & 40 & & 100 & Fusarium spp 100 \\
\hline & 7 & 60 & & 40 & & 100 & Cochliobolus sativus 40/ Fusarium spp 60 \\
\hline & 8 & 70 & & 30 & & 100 & Cochliobolus sativus 30/ Fusarium spp 70 \\
\hline & 9 & 70 & & 10 & & 100 & Cochliobolus sativus 30/ Fusarium spp 70 \\
\hline & 10 & 60 & & 10 & & 100 & Cochliobolus sativus 20/ Fusarium spp 80 \\
\hline \multirow{10}{*}{2015} & 1 & 100 & \multirow{10}{*}{90} & 100 & \multirow{10}{*}{87} & 50 & Cochliobolus sativus \\
\hline & 2 & 100 & & 100 & & 70 & Cochliobolus sativus \\
\hline & 3 & 70 & & 70 & & 30 & Cochliobolus sativus \\
\hline & 4 & 90 & & 90 & & 30 & Cochliobolus sativus \\
\hline & 5 & 90 & & 90 & & 50 & Cochliobolus sativus \\
\hline & 6 & 100 & & 90 & & 60 & Fusarium spp \\
\hline & 7 & 90 & & 90 & & 70 & Cochliobolus sativus \\
\hline & 8 & 90 & & 90 & & 50 & Cochliobolus sativus \\
\hline & 9 & 90 & & 80 & & 70 & Cochliobolus sativus \\
\hline & 10 & 80 & & 70 & & 60 & Cochliobolus sativus 10/ Fusarium spp 90 \\
\hline
\end{tabular}

As it is seen from Table 4, phytopathogenic fungi content from Benthe grains varies a lot depending on the harvesting year.

Ratio of samples with fusarial infection (the ratio of samples in sampling which have grains infected by fungi of Fusarium genus to the total amount of the analyzed samples, \%) for Benthe grade of 2015 harvesting year was just $10 \%$. From the other side, the ratio (frequency) of samples infected by Cochliobolus sativus in this year was $49 \%$.
For Benthe harvest of the year 2016 a reverse tendency is observed. Frequency of samples with fusarial contamination for Benthe of 2106 harvesting year was $69 \%$ and the ratio of samples infected by Cochliobolus sativus, was $31 \%$.

The ratio of samples with fusarial infection of Cherio grade of the 2015 harvesting year was $52 \%$, and the ratio of samples infected by Cochliobolus sativus was $48 \%$. The ratio of samples with fusarial infection of Cherio grade of the 2016 
harvesting year was $83 \%$, and the ratio of samples infected by Cochliobolus sativus was $17 \%$.
So we observed a clear increase of fungi of Fusarium genus in pathogenic mycobiota of grains of the year 2016 for both of the grades.

TABLE V. INTERNAL CONTAMINATION OF CHERIO COCHLIOBOLUS SATIVUS AND FUSARIUM SPP GRAINS

\begin{tabular}{|c|c|c|c|c|c|c|c|}
\hline Year & Dish No. & Sprouting, \% & $\mathrm{X}_{\mathrm{av}}$ & Germination ability, \% & $\mathrm{X}_{\mathrm{av}}$ & Infection rate, $\%$ & Species composition (\%) \\
\hline \multirow{10}{*}{2016} & 1 & 90 & \multirow{10}{*}{58} & 70 & \multirow{10}{*}{40} & 100 & Cochliobolus sativus 20/ Fusarium spp 80 \\
\hline & 2 & 40 & & 30 & & 100 & Cochliobolus sativus 10/ Fusarium spp 90 \\
\hline & 3 & 70 & & 40 & & 100 & Cochliobolus sativus 10 / Fusarium spp 90 \\
\hline & 4 & 60 & & 40 & & 100 & Cochliobolus sativus 20/ Fusarium spp 80 \\
\hline & 5 & 50 & & 20 & & 100 & Cochliobolus sativus 30/ Fusarium spp 70 \\
\hline & 6 & 50 & & 40 & & 100 & Fusarium spp 100 \\
\hline & 7 & 50 & & 40 & & 100 & Cochliobolus sativus 20/ Fusarium spp 80 \\
\hline & 8 & 60 & & 40 & & 100 & $\begin{array}{l}\text { Cochliobolus sativus } 30 / \\
\text { Fusarium spp } 70\end{array}$ \\
\hline & 9 & 70 & & 50 & & 100 & Cochliobolus sativus 10/ Fusarium spp 90 \\
\hline & 10 & 40 & & 30 & & 100 & Cochliobolus sativus 20/ Fusarium spp 80 \\
\hline \multirow{10}{*}{2015} & 1 & 70 & \multirow{10}{*}{68} & 50 & \multirow{10}{*}{46} & 100 & Cochliobolus sativus 40/ Fusarium spp 60 \\
\hline & 2 & 70 & & 30 & & 100 & Cochliobolus sativus 20/ Fusarium spp 80 \\
\hline & 3 & 60 & & 30 & & 100 & Cochliobolus sativus 70 / Fusarium spp 30 \\
\hline & 4 & 80 & & 50 & & 100 & Cochliobolus sativus 50/ Fusarium spp 50 \\
\hline & 5 & 70 & & 60 & & 100 & Cochliobolus sativus 70/ Fusarium spp 30 \\
\hline & 6 & 80 & & 60 & & 100 & Cochliobolus sativus 40/ Fusarium spp 60 \\
\hline & 7 & 60 & & 10 & & 100 & Cochliobolus sativus 70/ Fusarium spp 30 \\
\hline & 8 & 40 & & 30 & & 100 & Cochliobolus sativus 50/ Fusarium spp 50 \\
\hline & 9 & 70 & & 70 & & 100 & Cochliobolus sativus 20/ Fusarium spp 80 \\
\hline & 10 & 80 & & 70 & & 100 & Cochliobolus sativus 50/ Fusarium spp 50 \\
\hline
\end{tabular}

Simultaneousy with mycobiota investigations we considered such parameters as germination energy and ability for estimation of only internal mycobiotics influence after surface sterilization of seeds. For Benthe these parameters reliably varied depending on the harvesting year, which was proved by values of t-criterion of Student (for germination energy $t=6.7 \quad(\mathrm{P}<=005)$, for germination ability $\mathrm{t}=10.2$ $(\mathrm{P}<=0.05))$. For Cherio reliable values were not founded $(\mathrm{t}=$ 1.6 for germination energy and $t=0.8$ for germination ability $(\mathrm{P}>0.05))$.

Thus, sampling of the 2016 Benthe grains was reliably different from this grains of the 2015 harvesting year by high damage by Fusarium and Cochliobolus sativus fungi, as well as low sprouting germination ability and energy.

\section{A. Extraction of pathogen.}

The extracted fungi were subculturing for further investigation: DNA extraction and PCR statement with species-specific primers.

Fusarial fungi species vary according to activity of sporulating, and symptomes might be clearly observed or absent depending on the pathogen. At favorable conditions such species as F.avenaceum, F.graminearum, F.heterosporum, F.culmorum, easily form colored mass of macroconidiums both in natural conditions at plant tissue and in artificial nutrient broth. In areas of mass distribution of these species we see a clear sporulation in view of colored mass of macroconidiums at spicelet glumes [26].

But many species of fusarial fungi do not form macronidiums or form it rarely and instead of clearly observed rose blooms on spicelet glumes low-observable or noncharacteristic symtoms of infection are developed eyespot, necrotic darkening of spicelet glumes, stripe disease.

These symptoms of field investigation of inoculations can be easily mixed up with manifestations of other diseases, which are caused by fungi $p p$. Alternaria, Pyrenophora, Cladosporium, Cochliobolus. Often fusariousis occurs without any observable signs. For example, at plant infection by fungi $F$. tricinctum, F.poae, F. sporotrichioides, mycotoxins presence and high degree of pathogen infections are revealed only during mycotoxicological analysis of the collected grains. Even less noticeable are external signs of infection at late progression of fusarium [27]. 


\section{B. DNA extraction. PCR .}

We performed determination of species of Fusarium fungi which were extracted from Benthe and Cherio grains in the following way: from a dish with PGA of fungi culture we extracted total DNA and PCR used with species-specific primers $\mathrm{Fg} 11 \mathrm{f} / \mathrm{r}$, which allow one to identify toxigenic species Fusarium graminearum.

Results of PCR with species-specific primers for fungi extracted from Benthe of the year 2016 are presented in Fig. 1.

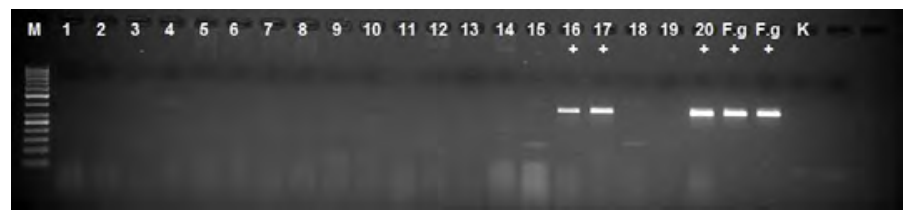

Fig. 1. Identification of Fusarium graminearum using species-specific primers Fg11f/r: M is marker of molecular weight $50 \mathrm{bp}$ «Fermentas», F.g is positive control Fusarium graminearum; $\mathrm{K}$ is negative control without DNA;

"+" states for presence of diagnostics fragment with molecular weight $500 \mathrm{bp}$.

\section{CONCLUSION}

We determined relation of fungi of Fusarium genus to a species Fusarium graminearum in samples Nos.16, 17 and 20 of Benthe grains of the 2016 harvesting year. Analogical work was carried out for fusarial fungi extracted from Cherio of the year 2016. As a result, in 9 of 16 analayzed samples (i.e. in $56.3 \%$ ) we identified toxigenic species Fusarium graminearum.

Consequently, usage of PCR as one of the nanobiotechnology technique allows one to perform the most accurate and reasonable diagnostics of toxigenic contaminants of material and prevent its usage in food industry.

\section{References}

[1] R. Ravichandran, "Nanotechnology Applications in Food and Food Processing: Innovative Green Approaches, Opportunities and Uncertainties for Global Market", Int. J. Green Nanotechnol. Phys. Chem., vol. 1, pp. 72-96, 2010.

[2] E. V. Preobrazhenskaya, I. V. Bizin, E. S. Kuligina, A. Y. Shleykina, E. N. Suspitsin, O. A. Zaytseva, E. I. Anisimova, S. A. Laptiev, T. V. Gorodnova, A. M. Belyaev, E. N. Imyanitov and A. P. Sokolenko, "Detection of BRCA1 gross rearrangements by droplet digital PCR", Breast Cancer Res. Treat., vol. 165, pp. 765-70, 2017

[3] V. Vermeeren, N. Bijnens, S. Wenmackers, M. Daenen, K. Haenen, O. A. Williams, M. Ameloot, A. Vandeven, P. Wagner and L. Michiels, "Towards a real-time, label-free, diamond-based DNA sensorle", Langmuir, vol. 23, pp. 13193-202, 2007

[4] M. A. Plotnikova, S. A. Klotchenko and A. V. Vasin, "Development of a multiplex quantitative PCR assay for the analysis of human cytokine gene expression in influenza A virus-infected cells", J. Immunol. Methods, vol. 430, pp. 51-5, 2016

[5] D. Germini, Y. Bou Saada, T. Tsfasman, K. Osina, C. Robin, N. Lomov, M. Rubtsov, N. Sjakste, M. Lipinski and Y. Vassetzky, "A OneStep PCR-Based Assay to Evaluate the Efficiency and Precision of Genomic DNA-Editing Tools", Mol. Ther. - Methods Clin. Dev., Vol. 5, pp. 43-50, 2017

[6] T. A. Shtam, R. B. Samsonov, A. V. Volnitskiy, R. A. Kamyshinsky, N. A. Verlov, M. S. Kniazeva, E. A. Korobkina, A. S. Orehov, A. L. Vasiliev, A. L. Konevega and A. V. Malek, "Isolation of Extracellular Microvesicles from Cell Culture Medium: Comparative Evaluation of
Methods", Biochem. Suppl. Ser. B Biomed. Chem., vol. 12, pp. 167-75, 2018.

[7] G. Mitina, I. Kazartsev, A. Vasileva and T. Yli-Mattila "Multilocus genotyping based species identification of entomopathogenic fungi of the genus Lecanicillium (=Verticillium lecanii s.l.)" J. Basic Microbiol., vol. 57, pp. 950-61, 2017

[8] A. V. Shcherbakov, E. N. Shcherbakova, S. A. Mulina, P. Y. Rots, R. F. Daryu, E. I. Kiprushkina, L. N. Gonchar and V. K. Chebotar, "Psychrophilic endophytic pseudomonas as potential agents in biocontrol of phytopathogenic and putrefactive microorganisms during potato storage", Sel'skokhozyaistvennaya Biol., vol. 52, pp. 116-28, 2017

[9] G. G. Panova, E. V. Kanash, K. N. Semenov, N. A. Charykov, Y. V. Khomyakov, L. M .Anikina, A. M. Artem'eva, D. L. Kornyukhin, V. E. Vertebnyi, N. G. Sinyavina, O. R. Udalova, N. A. Kulenova and S. Y. Blokhina, "Fullerene derivatives influence production process, growth and resistance to oxidative stress in barley and wheat plants", Sel'skokhozyaistvennaya Biol., vol. 53, pp.38-49, 2018

[10] F. G. Priest and I. Campbell (eds.), Brewing Microbiology. Springer Science \& Business Media, 2003

[11] S. V. Shvetsova, E. V. Zhurishkina, K. S. Bobrov, N. L. Ronzhina, I. M. Lapina, D. R. Ivanen, T. Y. Gagkaeva and A. A. Kulminskaya, "The novel strain Fusarium proliferatum LE1 (RCAM02409) produces $\alpha$-Lfucosidase and arylsulfatase during the growth on fucoidan", J. Basic Microbiol., vol. 55, pp. 471-9, 2015

[12] S. A. Korban, K. S. Bobrov, M. A. Maynskova, S. N. Naryzhny, O. L. Vlasova, E. V. Eneyskaya and A. A. Kulminskaya, "Heterologous expression in Pichia pastoris and biochemical characterization of the unmodified sulfatase from Fusarium proliferatum LE1", Protein Eng. Des. Sel., vol. 30, pp. 477-88, 2017

[13] P. M. Oliveira, A. Mauch, F. Jacob, D. M. Waters and E. K. Arendt "Fundamental study on the influence of Fusarium infection on quality and ultrastructure of barley malt", Int. J. Food Microbiol., vol. 156, pp. 32-43, 2012

[14] P. M. Oliveira, D. M. Waters and E. K. Arendt, "The impact of Fusarium culmorum infection on the protein fractions of raw barley and malted grains", Appl. Microbiol. Biotechnol., vol. 97, pp. 2053-65, 2013.

[15] E. A. Martynova and O. B. Ivanchenko, Biological effects of fumonusines and its contamination of grain products. Moscow: Nauchnaya monografiya, 2015

[16] O..B. Ivanchenko, R.A. Fedorova, Contamination of cereal crops with mycotoxins and safety of grain products, "News of the St. Petersburg State Agrarian University", vol. 31, pp. 47-52, 2013

[17] O. B. Ivanchenko and E.A. Martynova, "Impact of mycotoxine mikotoksina fumonisin B1 on proliferation and functional activity of Saccharomyces cerevisiae", Uspekhi Med. Mikol., vol. 13, pp. 337-9, 2014

[18] J. Peters, R. Van Dam, R. Van Doorn, D. Katerere, F. Berthiller, W. Haasnoot and M. W. F. Nielen, "Mycotoxin profiling of 1000 beer samples with a special focus on craft beer", PLoS One, vol. 12, pp.55, 2017

[19] J. Bellver Soto, M. Fernández-Franzón, M. J. Ruiz and A. Juan-García, "Presence of ochratoxin a (OTA) mycotoxin in alcoholic drinks from southern european countries: Wine and beer", J. Agric. Food Chem., vol. 62, pp.7643-51, 2014

[20] P. M. Scott, "Recent research on fumonisins: A review", Food Addit. Contam. - Part A Chem. Anal. Control. Expo. Risk Assess., vol. 29, pp. 242-8, 2012

[21] TP TC 021/2011 "On safety of food production"

[22] U. Saffiotti, "Evaluation of mixed exposure to carcinogens and correlations of in vivo and in vitro systems", Environ. Health Perspect. Vol. 47, pp. 319-24, 1983

[23] M. Mably, M. Mankotia, P. Cavlovic, J. Tam, L. Wong, P. Pantazopoulos, P. Calway and P. M. Scott, "Survey of aflatoxins in beer sold in Canada", Food Addit. Contam., vol. 22, pp.1252-7, 2005

[24] GOST 12036-85 "Seeds of crops. Acceptance procedures and methods of sampling (with Changes N 1,2)" 
[25] GOST 12038-84 "Seeds of crops. Methods of determination of viability"

[26] GOST 12037-81 "Seeds of crops. Methods of definition of purity and withdrawal of seeds"
[27] T. Y. Gagkaeva, O. P. Gavrilova, M. M. Levitin and K. V. Novozhilov, "Fusarios of grain cultures", Zashchita i karantin rastenij, vol. 5, pp.112, 2011

[28] M. G. Murray and W. F. Thompson, "Rapid isolation of high molecular weight plant”, Nucleic Acids Res., vol. 8, pp. 4321-6, 1980

[29] GOST 5060-86 "Malting barley. Specifications (with Change N 1)" 